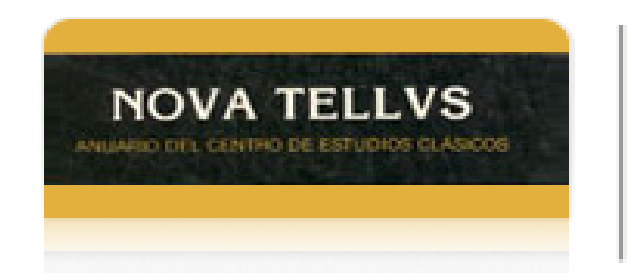

Nova Tellus

ISSN: 0185-3058

novatelu@servidor.unam.mx

Centro de Estudios Clásicos

México

Álvarez Salas, Omar

Teatro filosófico en Luciano y Alfonso Reyes: dos diálogos de 'Pitágoras'

Nova Tellus, vol. 26, núm. 2, 2008, pp. 271-292

Centro de Estudios Clásicos

Distrito Federal, México

Disponible en: http://www.redalyc.org/articulo.oa?id=59115497012

- Cómo citar el artículo

- Número completo

- Más información del artículo

- Página de la revista en redalyc.org

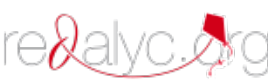

Sistema de Información Científica

Red de Revistas Científicas de América Latina, el Caribe, España y Portugal

Proyecto académico sin fines de lucro, desarrollado bajo la iniciativa de acceso abierto 


\title{
Teatro filosófico en Luciano y Alfonso Reyes: dos diálogos de 'Pitágoras'
}

\author{
Omar ÁlVAREz SALAS \\ Universidad Nacional Autónoma de México \\ omaralvar@hotmail.com
}

RESUMEN: En este trabajo se examinan dos recreaciones dramáticas de la figura de Pitágoras de Samos que, pese a las muy distintas intenciones de sus autores y a la distancia de 18 siglos que las separa, presentan un notable paralelismo en el tratamiento del personaje, lo que parece atribuible a la común dependencia, en ambos autores, de tradiciones escritas comparables. Del gran escritor y helenista mexicano Alfonso Reyes se considerará una bien lograda pieza, "Los filósofos de las islas", de la obra Junta de Sombras, donde éste representa al filósofo de Samos en diálogo con Jenófanes; dicha evocación será comparada con la Vitarum auctio de Luciano de Samosata, donde la figura de Pitágoras - que es por cierto una fuente de inspiración frecuente para este satirista - exhibe una fisonomía de derivación claramente libresca que, prescindiendo de su tono jocoso, se toca en muchos puntos con la reconstrucción 'filológica' del humanista regiomontano.

\begin{abstract}
In this article two dramatic sketches featuring Pythagoras of Samos are examined, both of which, in spite of the quite different purposes of their authors and of the intervening 18 centuries lapse of time between them, show a remarkable parallelism in the treatment of the character: this might be a result of the dependance, shared by both authors, on written traditions of much the same kind. "The philosophers of the islands", a brief masterpiece by Mexican writer and Greek scholar Alfonso Reyes taken from his work Junta de Sombras will be examined, where he depicts the philosopher of Samos in a dialog with Xenophanes. With this evocative piece by Reyes Lucian's Vitarum auctio will be compared, where Pythagoras's image - certainly a frequent source of inspiration for Lucian's satire - shows an outspoken bookish outlook, which, disregarding Lucian's humorous vein, matches in many ways to Alfonso Reyes' 'scholarly' reconstruction.
\end{abstract}

Palabras Clave: Alfonso Reyes, Ateneo de la Juventud, diálogo filosófico, Jenófanes, Junta de Sombras, Luciano de Samosata, Pitágoras, sátira, Vitarum auctio.

RECEPCIÓN: 5 de septiembre de 2008.

ACEPTACIÓN: 13 de octubre de 2008.

NOVA TELLVS, 26•2, 2008 


\title{
Teatro filosófico en Luciano y Alfonso Reyes: dos diálogos de 'Pitágoras'
}

\author{
Omar ÁlVAREz SALAS
}

En la sugestiva colección de ensayos que lleva por título Junta de Sombras, el gran escritor y helenista mexicano Alfonso Reyes, como parte de una serie de cuadros muy bien logrados sobre diversos aspectos de la cultura griega arcaica, nos entrega una pieza - el capítulo IX. "Los filósofos de las islas"que contiene una afortunada evocación del inmortal filósofo de Samos, representado dramáticamente en diálogo con Jenófanes. Dicho hipotético encuentro, como me propongo mostrar en estas páginas, no sólo es recreado por el humanista regiomontano con gran vitalidad creativa y envidiable maestría compositiva, sino que su ceñido apego a las fuentes históricas sobre la filosofía presocrática le permitieron dar a dicha pieza una fisonomía que recuerda de muchas maneras la jocosa precisión 'filológica' de Luciano de Samosata en su Vitarum auctio.

Ya el mismo epígrafe escogido por Reyes para Junta de Sombras, que esclarece de inmediato el título dado a su colección de textos, delata sin ambages que la ambición perseguida en ella por su autor consiste en invocar los 'espectros' de los grandes hombres de la Antigüedad griega, despertándolos del fantasmal letargo de Thánatos, para hacerles entablar un diálogo vivo frente al lector. La pertinencia de dicho pasaje para el examen que realizaremos en seguida nos persuade de reproducirlo completo aquí:

Llegado al brumoso país de los Cimerios, Odiseo cavó con su daga un ancho foso e hizo una libación a los muertos - miel, leche, 
vino y agua - desparramando encima la harina de las ofrendas rituales. Hizo luego traer de su nave las bestias destinadas al sacrificio, y las degolló junto al foso, llenándolo con la sangre humeante. Sedientos y anhelosos por recobrar un poco de vida, acudieron en torno al foso los difuntos, "cabezas sin vigor", venidos desde las profundidades del Érebo. Se precipitaban en multitud, lanzando tremendos alaridos. El "pálido terror" asomó al semblante del héroe que, desenvainando otra vez la daga, los iba obligando a turnarse para contestar a sus preguntas.

Resulta prácticamente ocioso señalar que el trozo transcrito arriba es nada menos que una paráfrasis bastante ajustada de Od., vv. 12-50, es decir, de los versos en que Homero introduce el episodio de la Nekyia: Odiseo, deseoso de obtener del fallecido adivino Tiresias información sobre la ruta de regreso a Ítaca, practica un rito de necromancia destinado a llamar a las almas de los muertos, sumidas en la oscuridad del Érebo, a algunas de las cuales devuelve momentáneamente la conciencia, dándoles a beber la sangre de un animal sacrificado, para conversar con ellas. Por lo demás, el reflejo fiel del sentido implícito en el texto homérico es subrayado por Reyes a través de dos sintagmas formulaicos de especial efecto icástico, que traslada literalmente del griego: "cabezas sin vigor"

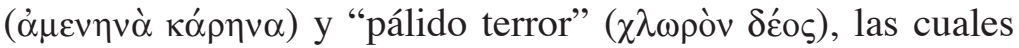
describen de manera insuperable el estado psicológico en que se encuentran, respectivamente, los languidecientes espectros de los difuntos, eí $\delta \omega \lambda \alpha$ privados de fuerza vital, y el azorado intruso que osa hollar antes de tiempo la morada de Hades.

La alusión al encuentro de Odiseo con las sombras de los desaparecidos marca, pues, la pauta del procedimiento de evocación literaria que guió a Alfonso Reyes en la redacción de Junta de Sombras, quien lo emplea con especial éxito en su diálogo imaginario entre Pitágoras y Jenófanes, por más que lo deje asomarse ocasionalmente en otras piezas y esté también implícito en la concepción global del libro. A través de la aparición "directa" de los dos filósofos, sin embargo, nuestro autor 
lleva a cabo una doble y más íntima conexión con la inspiración helénica de su texto, ya que no sólo los personajes y el contenido de la conversación que entablan provienen de la Antigüedad griega misma, sino que el propio mecanismo literario de atribuir un discurso, real o ficticio, a un personaje vivo o muerto, ausente, en todo caso, que es, por decirlo así, "puesto en escena", es una vieja herencia de la literatura griega arcaica, donde conoció un especial desarrollo en la poesía de escarnio.

El artificio de la persona loquens es, en efecto, un recurso utilizado ya por la épica homérica, en donde el dramatismo de tantos momentos es subrayado mediante la introducción de un diálogo - de mayor o menor verosimilitud y pertinenciaentre los protagonistas, cuyas palabras los caracterizan psicológicamente haciendo que sus acciones cobren vida en el ámbito de la obra escrita. ${ }^{1}$ Más tarde, la poesía satírica explotaría de manera particularmente amplia el uso de la primera persona para atribuir a un personaje distinto del autor, por lo general un adversario o rival, discursos fingidos sobre todo con fines de denigración o calumnia. ${ }^{2}$ Con tal procedimiento es también

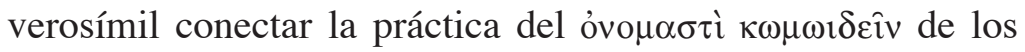
autores de la Comedia Antigua, quienes, para fustigar más eficazmente el blanco de su crítica, solían a menudo llevar al escenario a la persona misma que era objeto del ridículo, atribuyéndole acciones y palabras acordes con su imagen tradicional o, más bien, con la que le querían formar. ${ }^{3}$ Finalmente, el receptor natural de dicho mecanismo literario de puesta en

\footnotetext{
${ }^{1}$ Dicho procedimiento será heredado también por los historiadores, que insertan discursos en el relato de los hechos para devolver la dimensión dramática a un suceso pasado, de lo que hay abundantes ejemplos sobre todo en Heródoto.

${ }^{2}$ Piénsese, por ejemplo, en ciertos fragmentos 'dramáticos' de Arquíloco (19 W., sobre lo cual véase Arist., Rhet., 3. 1418 b 23 ss.) o de Alceo (p. ej. el 10B L.-P.) en los que el 'blanco' de la denigración habla en primera persona.

${ }^{3}$ El caso más sonado de representación en la escena cómica de un personaje real, a quien se pone en ridículo mediante la atribución abusiva de palabras y acciones, es la imagen de Sócrates creada por Aristófanes en las Nubes, si bien no fue éste un caso aislado ni único en la Comedia Antigua.
} 
escena de personajes que alguna vez existieron fue el diálogo literario en prosa, desarrollado sobre todo por los socráticos, con Platón a la cabeza: este último, en efecto, representó en conversación con su maestro, además de la vasta cohorte de intelectuales de todo tipo que efectivamente residieron en (o se movieron alrededor de) Atenas, incluso al propio Parménides de Elea, pese a que difícilmente éste se hubiera trasladado a tan grande distancia sólo para platicar sobre la teoría de las ideas platónicas con el joven prodigio Sócrates. ${ }^{4}$

Dados estos precedentes helénicos de diálogos que involucran concepciones filosóficas algo o muy sofisticadas, llama mucho la atención que la conversación ideada por Reyes entre Pitágoras y Jenófanes, donde el filósofo de Samos se ve involucrado en un intercambio polémico de opiniones sobre sus respectivas doctrinas, por las que cada quien tiene que abogar frente a un interlocutor escéptico o incluso francamente adverso, encuentre un interesante paralelo en una obra redactada por un maestro en el arte de la escritura irónica en lengua griega, de la época imperial. Nos referimos nada menos que a Luciano de Samosata, consumado maestro en la composición de diálogos con fuerte carga satírica, inspirados en la obra, para nosotros perdida, del cínico Menipo de Gadara. Al parecer siguiendo el ejemplo de éste, Luciano dedicó una parte importante de sus obras a poner al descubierto la artificialidad y vacuidad de las posturas adoptadas por los hombres, entre las que nos interesa resaltar aquí sobre todo las geniales caricaturas que hizo de los presuntos adeptos de las numerosas escuelas filosóficas conocidas en su época.

Pues bien, como parte de su movilización literaria para desenmascarar las falsas actitudes de las masas de pseudo-filósofos que pululaban en el siglo II d.C., Luciano escribió un

\footnotetext{
${ }^{4}$ La lista de personajes reales que Platón lleva a su 'escena' dialógica, atribuyéndoles conversaciones ficticias, aunque verosímiles, con fines prevalentemente denigratorios (sobre todo en el caso de los llamados sofistas), es tan larga y famosa que podemos prescindir aquí de ella.
} 


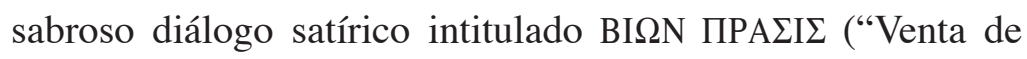
vidas", en traducción literal), citado sobre todo bajo la forma latina Vitarum auctio o "Subasta de vidas". En este texto, el ingenioso escritor de Samosata pone en escena a Zeus y a Hermes en el acto de organizar una venta pública de vidas filosóficas, es decir, de los regímenes de conducta preconizados por las famosas escuelas de las diferentes épocas, proyectadas de manera emblemática por Luciano bajo el nombre de su respectivo fundador o de su representante más destacado. No es sorprendente, entonces, que la primera "vida" en ser puesta a la venta en dicha subasta sea la pitagórica, cuya posición de relieve se debe no sólo a la influencia de la doctrina original inculcada por Pitágoras a sus primeros discípulos en Magna Grecia entre los siglos VI-V a.C., sino también a su notable pervivencia posterior, sobre todo en simbiosis con el platonismo. En efecto, fue tan extraordinario el empuje de ese pitagorismo platonizante que llegó a ser revivido de nuevo, si bien en forma profundamente alterada, por el llamado neopitagorismo del siglo I a.C., para ser de nuevo impulsado entre los siglos III-IV d.C. por los neoplatónicos Porfirio y Jámblico. Así pues, es muy comprensible que la figura de Pitágoras apareciera en primer plano en la BI $\Omega N$ ПPA $\Sigma I \Sigma$ de Luciano, donde se representa al filósofo exponiendo "en vivo", ante un posible comprador, el abanico de doctrinas que entonces se ima-

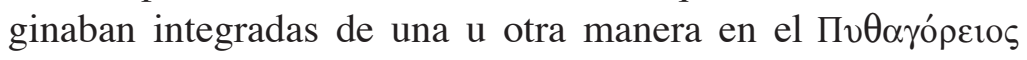

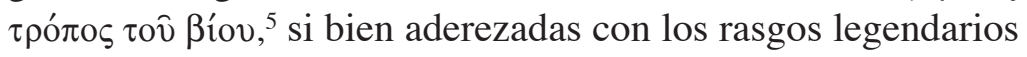
que la tradición enaltecedora del gran sabio de Samos había ya dejado asociados con su nombre. Esto se puede apreciar, en efecto, en el pasaje inicial de la obra citada de Luciano, donde el protagonista es justamente Pitágoras, fragmento que transcribimos en seguida, en nuestra propia traducción, indicando en nota para comodidad del lector las fuentes que confirman

\footnotetext{
${ }^{5}$ La expresión se remonta a Platón (Resp., 600 a-b), que documenta expresamente la persistencia de una "forma de vida pitagórica" todavía en el siglo IV a.C.
} 
(o, cuando menos, justifican) las informaciones proporcionadas por Luciano:

ZeUS: Tú, acomoda los bancos y prepara el lugar para los que van llegando, y tú, trae al frente las vidas y ponlas en hilera, no sin antes acicalarlas, que así tendrán un aspecto más hermoso y atraerán al mayor número posible. Tú, Hermes, haz de pregonero y convócalos.

HeRmes: Por buena suerte los compradores ya se encuentran en el sitio de remates. Pondremos en venta vidas filosóficas de todo tipo y de varios sistemas ideológicos. Y si alguien no puede pagar en efectivo al momento, que designe un garante y liquide el año próximo.

ZEuS: Se están juntando muchos, así que no hay que perder tiempo ni retener a éstos. ¡Vendamos pues!

HERMES: ¿A quién quieres que traigamos delante primero?

ZEUS: Al melenudo este, el jonio, ya que parece ser un personaje de porte distinguido. ${ }^{6}$

Hermes: Tú, pitagórico, avanza y ponte para que te examinen los aquí reunidos.

Zeus: Haz el pregón.

HeRmes: Vendo la vida de más alta calidad, la más distinguida. ¿Quién la compra? ¿Quién quiere ser más que un humano $?^{7}$ ¿Quién quiere conocer la armonía del universo y renacer de nuevo? ${ }^{8}$

\footnotetext{
${ }^{6}$ Pitágoras era, en efecto, un jonio de Samos, como confirman casi unánimemente las fuentes más antiguas (cf. Herod., IV 95; Isocr., Bus., 28), y en dialecto jonio lo hace hablar el propio Luciano - las ocasionales indicaciones de un origen 'barbaro' parecen invención tardía (Clem. Al., Strom., I 62; D.L. VIII 1), quizá como justificación a posteriori de la 'quimera' intelectual de Pitágoras - . Por su

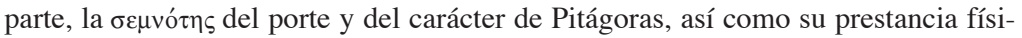
ca, están bien atestiguadas (D.L. VIII 56; Porphyr., V. Pyth., 18 - cf. Isocr., Bus., 28) y parecen provenir de una tradición que se remonta por lo menos al s. IV a.C.

${ }^{7}$ La superioridad física e intelectual de Pitágoras es un rasgo fijo asociado con su imagen ya desde el s. v a.C. (Emp. 31 B 129 D.-K.), de la que se puede ver un reflejo en la doctrina 'secreta', mencionada por Aristóteles (fr. 192, ap. Iambl., V.P., 31), según la cual habría tres categorías de ser racional: dios, hombre y como Pitágoras.

${ }^{8}$ La capacidad de escuchar la armonía del universo aparece conectada en las fuentes con la superior constitución física e intelectiva de Pitágoras (Porphyr., V.
} 
COMPRADOR: Por el aspecto no carece de nobleza. ¿Cuál es su conocimiento más sobresaliente?

HeRMEs: Aritmética, astronomía, geometría, taumaturgia, música, superchería. Estás viendo a un profeta insuperable. $^{9}$

COMPRADOR: ¿Está permitido interrogarlo?

HERMES: Interrógalo y ¡buena suerte!

COMPRADOR: ¿De dónde eres?

PITÁgORAS: De Samos

COMPRADOR: ¿Dónde fuiste educado?

PitÁGORAs: En Egipto, con los sabios locales. ${ }^{10}$

COMPRADOR: Veamos, si te compro, ¿qué me enseñarás?

PITÁGORAS: No te enseñaré nada, sino te haré recordar. ${ }^{11}$

COMPRADOR: ¿Cómo me harás recordar?

PITÁGORAS: Purificando tu alma primero y enjuagando la suciedad que tiene. ${ }^{12}$

Pyth., 30, que cita Emp. 31 B 129 D.-K.); además, está bien atestiguado el desarrollo entre los pitagóricos de una teoría matemática de los intervalos musicales y de un movimiento armónico de los astros (Arist., Metaph., A 5.985 b 23; de caelo B 9. 290 b 12). Por otro lado, la palingenesia o renacimiento del alma en otro cuerpo es el rasgo más característico de la doctrina original de Pitágoras, que aparece documentado ya por Jenófanes, en el siglo vi a.C. (Xen. 21 B 7 D.-K.).

${ }^{9}$ Aquí Luciano enumera los cuatro $\mu \alpha \theta \dot{\eta} \mu \alpha \tau \alpha$ canónicos del pitagorismo: aritmética, astronomía, geometría y música (para esto véase el importante fragmento 1 del pitagórico Arquitas de Tarento 47 B 1 D.-K.), entreverando sarcásticamente la "taumaturgia" y la "superchería", que son dos rasgos 'negativos' que fueron asociados muy pronto con Pitágoras y sus prácticas (poco honestas) de captación del interés público, según parece atestiguar ya Heráclito (22 B 81; 129; cf. 22 B 28). La tradición tardía retuvo sobre todo esta faceta mántica y taumatúrgica de Pitágoras ya documentada por Aristóteles (Pyth. 14 A 7 D.-K.).

${ }^{10}$ El testimonio más antiguo de un presunto viaje de Pitágoras a Egipto es Isocr., Bus., 28 (cf. Herod., II 123).

${ }^{11}$ La valoración de la memoria y la práctica cotidiana entre los pitagóricos de la

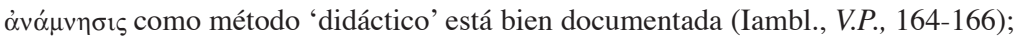
por lo demás, Emp. 31 B 129 D.-K. parece referirse a la capacidad de ỏvó $\mu v \eta \sigma i \varsigma$ de Pitágoras, por la cual se habría remontado al conocimiento adquirido en sus existencias previas (cf. Heráclides Póntico, ap. D.L. VIII 4), lo que establece un vínculo fuerte entre su incesante búsqueda de saber y su doctrina de la transmigración de las almas.

${ }^{12}$ La purificación espiritual perseguida a través del ejercicio de una disciplina física y mental rigurosa es un tema dominante y recurrente en las fuentes tardías sobre el pitagorismo (Iambl., V.P., 163 ss.). 
COMPRADOR: Bien, pues, supón que ya quedé purificado, ¿de qué manera me harías recordar?

PITÁGORAS: Al principio un largo silencio y mutismo, y durante cinco años completos nada de charlar. ${ }^{13}$

COMPRADOR: Querido amigo, sería bueno que instruyeras al hijo de Creso. Yo quiero ser platicador, no una estatua. Sin embargo, ¿qué viene después del silencio y de los cinco años?

PITÁGORAS: Te ejercitarás en la música y en la geometría.

COMPRADOR: ¡Estás diciendo una chulada, si he de volverme un citarista y luego un sabio!

PitÁGoras: Luego, además de esto, te ejercitarás en el arte de contar.

COMPRADOR: Ya sé contar ahora.

Pitágoras ¿Cómo cuentas?

COMPRADOR: Uno, dos, tres, cuatro.

PitÁGoras: ¿Ves? Los que tú crees que son cuatro en realidad son diez y constituyen un triángulo perfecto y nuestro juramento. ${ }^{14}$

COMPRADOR: Cierto, por el supremo juramento del cuatro, nunca escuché palabras más divinas ni más sagradas.

PITÁGORAS: Después, amigo, acerca de la tierra y el aire y el agua y el fuego aprenderás cuál es su comportamiento y en virtud de la forma que tienen cómo se mueven. ${ }^{15}$

\footnotetext{
${ }^{13}$ El silencio pitagórico, que ya en Isócrates (Bus., 28) aparece como un rasgo característico de la secta, es consistentemente descrito por los biógrafos neoplatónicos de Pitágoras como parte de las pruebas de ingreso a que éste sometía a quienes querían convertirse en miembros de su 'escuela'.

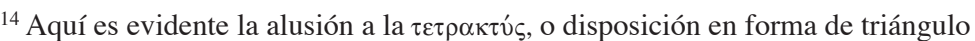

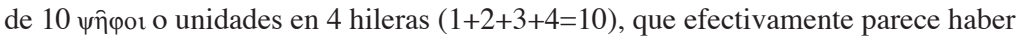
sido utilizada como juramento de los pitagóricos (Aët., I 3, 8; Luc., de lapsu in sal., 5) y estaba cargada de importantes simbologías aritmológicas (sobre el valor atribuido al número 10, ver infra la nota 37 al diálogo entre Pitágoras y Jenófanes escrito por A. Reyes).

${ }^{15}$ La constitución de los cuatro 'elementos' a partir de sólidos geométricos formados a través de una progresión que parte del punto y pasa por la recta y el plano es una doctrina pitagórica bien documentada (Platón la recoge en Tim., 53 c, y Aristóteles la menciona anónimamente en de caelo, III 1, 298b 33, y en Met., V 8, 1017
} 
COMPRADOR: ¿Entonces tienen forma el fuego o el aire o el agua?

PITÁGORAS: Y muy evidente: pues en la informidad y la disformidad no se podrían mover. Y además de eso aprenderás que dios es número e intelecto y armonía. ${ }^{16}$

COMPRADOR: Me estás diciendo cosas maravillosas.

PITÁGORAS: Adicionalmente a esto que ya dije aprenderás que tú, por más que piensas ser uno y el mismo, te ves como uno pero en realidad eres otro. ${ }^{17}$

COMPRADOR: ¿Qué dices? ¿Soy otro y no la persona que ahora habla contigo?

PITÁgoras: Ahora eres ése, en otro tiempo te manifestabas en otro cuerpo y bajo otro nombre. Con el tiempo, nuevamente, transmigrarás a otra persona.

COMPRADOR: ¿Estás diciendo que seré inmortal mientras voy cambiando a muchas formas? Es suficiente con esto. ¿Cuál es tu postura en lo relativo al régimen?

PITÁGORAS: No como nada que tenga vida, pero sí todo lo demás, excepto habas. ${ }^{18}$

COMPRADOR: ¿Por qué? ¿Acaso sientes horror por las habas?

PITÁGORAS: No, sino porque son sagradas y su naturaleza es maravillosa: al principio, en efecto, éstas son todo un órgano reproductivo, ${ }^{19}$ y si pelas un haba todavía verde verás que su constitución es similar

b 18-20), que aparece descrita con detalle en D.L. VIII 24 (a partir de unos escritos pitagóricos de un cierto Alejandro Polyhistor —cf. Philol. 44 B 12 D.-K.).

${ }^{16}$ Para la concepción pitagórica que ve en dios una suma de número, intelecto y armonía léase, p. ej., Aët., I 3, 8 (= Pythagoreische Schule 58 B 15 D.-K.), donde se mencionan también las especulaciones aritmológicas a las que nos referiremos abajo a propósito del texto de Alfonso Reyes.

${ }^{17}$ En virtud de la transmigración del alma se presenta una paradójica alteridad consigo mismo: Pitágoras, sin embargo, tenía la capacidad no sólo de remontarse a sus existencia previas (Emp. 31 B 129 D.-K.; cf. Emp. 31 B 117 D.-K.), sino de 'recordar' a otros quiénes habían sido en otras vidas (Xen. 21 B 7 D.-K.; Pyth., 14, test. 7, de Aristóteles).

${ }^{18}$ El vegetarianismo como régimen alimenticio (ritual) de Pitágoras y sus seguidores tiene un estrecho vínculo con la transmigración de las almas y aparece documentado desde el siglo IV a.C. (Eudoxo fr. 36 ap. Porphyr., V. Pyth., 6), al igual que la abstención de comer habas (Callim., fr. 128) también preconizada por Empédocles (31 B 141 D.-K.).

${ }^{19}$ Cf. Gellius, IV 11, 9, que transmite y comenta Emp. 31 B 141 D.-K. 
a la de las partes viriles; si las cueces y las dejas al claro de luna por una cantidad determinada de noches, las harás tornarse de color rojo sangre. La razón de más peso es que los atenienses tienen por ley elegir sus magistrados con habas.

COMPRADOR: Todo lo expusiste magníficamente y como conviene a un tema sagrado. Pero desvístete, porque quiero verte desnudo. ¡Heracles! Su muslo es de oro. ${ }^{20}$ Parece ser un dios, no un mortal, así que lo compro sin duda alguna. ¿Por cuánto lo estás vendiendo?

HeRmes: Por diez minas.

COMPRADOR: Lo tomo pagando ese precio.

Zeus: Escribe el nombre del comprador y su procedencia.

HeRMES: Parece ser un itálico, Zeus, de los que viven por Crotona y Tarento y en la Grecia de esa región. Sin embargo, lo compraron en forma mancomunada no uno sino cerca de trescientos. ${ }^{21}$

Zeus: Que se lo lleven. Traigamos a otro al frente.

Aquí termina la aparición en escena de Pitágoras. Ahora bien, prescindiendo de la generosa dosis de ironía que destila de la pluma de Luciano, sobre todo perceptible en su tratamiento de las doctrinas escatológicas y de los tabúes dietéticos de la secta pitagórica, así como de los rasgos divinos atribuidos a Pitágoras por su leyenda, hay que reconocer que el panorama doctrinario que se desprende de su diálogo corresponde bastante bien a la tradición (fragmentaria) que sobre el pitagorismo ha llegado hasta nosotros. Una comparación con los testimonios sobrevivientes - una selección de los cuales se menciona en

\footnotetext{
${ }^{20}$ Una más de las anécdotas recogidas por Aristóteles sobre prodigios de Pitágoras narra cómo en el teatro éste habría mostrado a los asistentes su muslo que era "como de oro" (Pyth. 14 A 7 D.-K.).

${ }^{21}$ Efectivamente, Pitágoras emigró a Crotona hacia el 540 a.C. donde en breve tiempo habría reunido a un gran número de seguidores (Porphyr., V. Pyth., 18-19), cuyo número, según una noticia bastante difundida (Iambl., V.P., 254) "habría rebasado los $300 "$.
} 
las notas al texto - mostraría, en efecto, que Luciano parece haber tenido a su disposición documentos con más o menos las mismas características de los que nosotros conocemos, que él recogió e integró con bastante fidelidad en su diálogo, haciendo abstracción de la creatividad jocosa de sus alusiones. Se trata, podemos afirmar, de una recreación 'filológica' de la figura de Pitágoras, comprensible en un autor como él, plenamente inmerso en un mundo libresco, que vio además poderosamente aguijoneada su imaginación hacia la reelaboración satírica de material pitagórico, como demuestra en particular otra de sus obras de la misma inspiración: El sueño o el gallo. ${ }^{22}$ Así pues, Luciano se reveló capaz de captar eficazmente la esencia de la doctrina pitagórica y de traducirla en materia para su sabrosa sátira, que no deja fuera ningún tema potencialmente explotable, y que, por ende, en los grandes filósofos de antaño, pero sobre todo en sus poco dotados y numerosos epígonos en tiempos del imperio romano, encuentra una veta riquísima para la producción de cuadros satíricos.

Pasemos ahora a examinar la recreación dramática de Pitágoras hecha por Alfonso Reyes. Éste, en efecto, como hombre profundamente empapado de lecturas antiguas y modernas, no descuidó ni siquiera a los más antiguos filósofos griegos, de quienes se preocupó por estudiar las citas dispersas que nos llegaron en autores posteriores, con todo y que, a principios del siglo Xx, no se disponía de una gama tan vasta como la que ahora poseemos de ediciones e instrumentos críticos. Pero entonces se vivían los tiempos gloriosos del Ateneo de la Juventud, con sus grandes esperanzas en la renovación de la cultura nacional mexicana a través de la profusión generosa del espíritu griego y de su mensaje liberador de la conciencia. Así pues, como "buen hijo de Grecia" que era, empujado por su deseo de penetrar a fondo en la cultura helénica, que tan

\footnotetext{
${ }^{22}$ En este largo diálogo, el protagonista es justamente un gallo, quien afirma ser la reencarnación del propio Pitágoras, a cuya figura y doctrinas hay frecuentes alusiones a lo largo de la obra.
} 
prometedores frutos ofrecía para el desarrollo de su proyecto intelectual y para la extensión de los ideales ateneístas, Reyes abordó con gran denuedo también el estudio del pensamiento griego. Para ello, dedicó importantes esfuerzos a la delimitación de esas figuras más bien vaporosas e inasibles de pensadores arcaicos que la historiografía del siglo XVIII, con sus esfuerzos de reestructuración de la conciencia histórica y por su búsqueda paralela de una periodización que reflejara dicho cambio de enfoque, asignó a una nueva entidad llamada "filosofía presocrática". ${ }^{23}$ Los estudios de Alfonso Reyes en este ámbito, si bien no alcanzaron una mole tal como para llenar por sí solos un libro, cristalizaron como sea en sendas secciones de dos importantes trabajos: La crítica en la edad ateniense (1941) y Junta de Sombras (1949). Está naturalmente fuera de nuestro objetivo presente ocuparnos en detalle del contenido y del espíritu de los diferentes ensayos que, en uno y otro libro del regiomontano, están dedicados a condensar las aportaciones intelectuales de los presocráticos, por lo que nos concentraremos aquí en la segunda parte del capítulo IX del libro mencionado en último término.

En el ensayo en cuestión, intitulado "Los filósofos de las islas" y claramente concebido como un texto de divulgación cultural, Reyes trata de presentar un cuadro en la medida de lo posible completo - pero libre de convencionalismos terminológicos y de esquematismos manualísticos - de las aportaciones de dos filósofos originarios de la Jonia insular y minorasiática,

\footnotetext{
${ }^{23}$ Para el surgimiento de la categoría historiográfica de los "presocráticos" véase A. Laks, "«Philosophes Présocratiques»: Remarques sur la construction d'une catégorie de l'historiographie philosophique", en A. Laks-C. Louguet (eds.), Qu'estce que la philosophie présocratique?, Lille, 2002, pp. 17-38: ahí se la explica como una construcción de la ciencia del siglo XVIII, que rompe con la dicotomía tradicional, heredada de Diógenes Laercio, que distingue entre la rama jónica (que se inicia con Anaximandro o con Tales y que, pasando por Sócrates, desemboca en la Academia de Platón y en el Perípato de Aristóteles) y la rama itálica iniciada por Pitágoras (con el antecedente de Ferécides), cuyo escenario será la Magna Grecia y Sicilia y comprende a personajes como Parménides y Empédocles.
} 
respectivamente: Pitágoras de Samos y Jenófanes de Colofón. Además de la vecindad de los sitios de origen, ambos personajes tienen en común, como acertadamente subraya el ateneísta, el haber emigrado hacia el Occidente, para buscar una nueva patria en la famosa Magna Grecia (Italia meridional), entonces pletórica de fundaciones coloniales griegas. Pitágoras la encontró de inmediato en Crotona, donde tras ganarse al senado local y atraerse con sus cautivadores discursos a una multitud de todas las edades y condiciones sociales, organizó una comunidad de vida y doctrina, que podría considerarse como la primera 'escuela' de Occidente. Jenófanes, en cambio, por su postura severamente crítica y demasiado anti-convencional como para lograr echar raíces en un solo lugar, se convirtió en un poeta errante que recorrió innumerables ciudades itálicas y sicilianas, difundiendo su revolucionario mensaje en forma de cáusticos poemas satíricos. La confrontación ideológica entre ambos era inevitable, pese a su común interés en la renovación moral del individuo y de la sociedad, pues para ganar credibilidad frente al público había que demostrar a toda costa que la propia propuesta era mejor que la del competidor. Por consiguiente, Alfonso Reyes, que estaba bien enterado acerca de la polémica de Jenófanes en contra de Pitágoras, ${ }^{24}$ imagina un encuentro de los dos hombres, ya algo ancianos, en una playa italiana, atribuyéndoles el diálogo transcrito abajo, basado presumiblemente en los testimonios y fragmentos que indicamos en las notas. El diálogo, por consiguiente, se presenta denso de referencias a los especímenes textuales de aquellos pensadores llegados hasta nosotros, o, en su defecto, a la doxografía que sintetiza (y no raramente deforma) su doctrina:

J(ENÓFANES). Hablemos como la buena gente en torno al fogón, mientras se cuela el dulce vino y se tuestan los garbanzos. ¿De dónde eres, y qué edad tenías cuando llegó el medo? ${ }^{25}$

\footnotetext{
${ }^{24}$ D.L. IX 18 y VIII 36.

${ }^{25}$ Paráfrasis de Xen. 21 B 22 D.-K.
} 
P(ITÁGORAS). De Samos, que dejé por asco del tirano Polícrates, y soy, según creo, de tu misma edad. ${ }^{26}$

J. ¿Qué verdad escondes bajo tu manto?

P. Una que no verán tus ojos: que el rectángulo isósceles no se deja reducir al número, pues sacando la razón cuadrada de la hipotenusa y los catetos, hallo que un número puede ser par e impar indistintamente. ${ }^{27}$ Sin embargo, existe ese triángulo. ¿Luego la realidad no es necesariamente convertible en inteligencia? Esto me conturba. ${ }^{28}$

J. ¿Por eso resuellas con tanto anhelo?

P. No. Resuello para purificarme. Resuello porque soy un $\operatorname{dios}^{29}$

${ }^{26}$ Porphyr., V. Pyth., 9: este testimonio, que informa sobre la salida de Pitágoras de Samos como disidente político a la toma del poder por parte de Polícrates (poco después del 540 a.C.), indica también que su edad era de 40 años, lo que permite colocar su nacimiento hacia el 580 a.C.; por su parte, el nacimiento de Jenófanes, combinando sus propias indicaciones (Xen. 21 B 8 D.-K.) con evidencias externas (para esto véase, entre otros trabajos, O. Álvarez, "Epicarmo e Senofane: tessere di una polemica", Noua tellus, 25-2, 2007, pp. 85-136), se puede datar en 571 a.C.

${ }^{27}$ Aquí hay una referencia a los números 'irracionales' o óp $\rho \eta \tau \alpha$ (de donde la duda de 'Pitágoras' sobre la traducción de la realidad en inteligencia), de los que los pitagóricos descubrieron al menos $\sqrt{2}$ : la demostración original, hecha sobre un triángulo rectángulo isósceles (es decir, la mitad de un cuadrado dividido por su diagonal), habría procedido por reducción al absurdo, mostrando que su hipotenusa es inconmensurable con el lado (o cateto), porque para ser conmensurable con éste tendría que ser al mismo tiempo par e impar (Arist., Anal. Pr., I 23, 41 a 26-27; cf. Eucl., Elem., App. 27). Un problema vinculado con éste - el de la construcción de un cuadrado cuya superficie sea el doble de un cuadrado dado- es planteado y resuelto de manera heurística por Platón en Men., 81c-85b.

${ }^{28}$ Se piensa generalmente que el descubrimiento de la inconmensurabilidad y de los números irracionales habría producido una profunda 'crisis' en la matemática pitagórica, a tal grado que hay una tradición según la cual aquel que reveló la inconmensurabilidad a los 'indignos' (a los no pitagóricos) habría sido no sólo excluido de la comunidad pitagórica, sino que se le habría hecho una tumba (Iambl., V.P., 246). Una variante de la noticia, que identifica al divulgador abusivo con Hípaso de Metaponto, quiere que éste haya perecido en el mar como 'impío' (Iambl., V.P., 247; Iambl., de comm. math. sc., 25).

${ }^{29}$ Para esto, compárese Emp. 31 B 129 D.-K. (ya citado arriba en el contexto del diálogo de Luciano), que también se presentaba a sí mismo como un "dios inmortal" (31 B 112, v. 4 D.-K.), así como la tripartición pitagórica del ser racional mencionada por Aristóteles: dios, hombre y como Pitágoras (fr. 192, ap. Iambl., V.P., 31). 
J. ¿Como en las patrañas poéticas? $?^{30}$

P. Tampoco. Soy dios espiritual opreso en la materia, y que quisiera regresar a su alto destino. ${ }^{31}$

J. ¡Seríamos entonces muchos dioses! Dios es uno y se compone de toda la materia y todo el espíritu a un tiempo. Y nunca se mueve, porque sólo lo particular se mueve respecto a lo particular, y Dios es toda la moción junta. Dios es eterno e increado. ${ }^{32}$ En fin, que de Él sólo sabemos que nada sabemos, y se me ocurre que lo mismo dirán los filósofos de mañana. ${ }^{33}$

P. Pero en ese infinito aéreo, que es el Todo, la naturaleza recorta y limita cosas particulares. El aire mide los intervalos, dándonos la música y el número. ${ }^{34} \mathrm{Y}$ respirar es divinizarse. ${ }^{35}$

J. Dios no respira porque es la Unidad que llena el Todo. ${ }^{36}$

\footnotetext{
${ }^{30}$ La hostilidad de Jenófanes hacia la mitología tradicional es uno de sus rasgos más característicos (D.L. IX 18; cf. Xen. 21 B 10-16, 23-25 y 32-34).

${ }^{31}$ En la doctrina pitagórica de la metempsícosis estaba contenida la concepción de que el alma humana es inmortal por ser un fragmento del alma cósmica, a la que aspira a regresar una vez purificada y liberada de las ataduras terrenales del cuerpo (Philol. 44 B 14-15 D.-K.; cf. Sext., adv. math., IX 127; D.L. VIII 24-33).

${ }^{32}$ Acerca de la concepción del dios único, inmóvil y eterno de Jenófanes que se perfila en sus fragmentos literales (Xen. 21 B 23-26) nos informa detalladamente el tratado pseudo-aristotélico de Melisso Xenophane Gorgia, c. 3.

${ }^{33}$ El escepticismo gnoseológico de Jenófanes se manifiesta expresamente en Xen. 21 B 34-35 D.-K.; el filósofo posterior que retomaría su concepción de la imposibilidad del conocimiento humano sería Sócrates, una conexión que al parecer se debe al propio Reyes.

${ }^{34}$ Hay aquí una alusión a la teoría matemática de los intervalos musicales desarrollada por los pitagóricos (Philol. 44 B 6 D.-K.; Archyt. 47 B 1 -cf. Ptolem., Harm., I 13, p. 30, 9).

${ }^{35}$ Reyes parece haber combinado aquí la concepción de la respiración cósmica de los pitagóricos (Arist., Phys., $\Delta 6.213$ b 22) con la doctrina de que "todo el aire está lleno de almas" (D.L. VIII 32), las cuales son fragmentos de éter divino y, por ende, 'absorbibles' o 'inhalables'.

${ }^{36}$ Los estudiosos aceptan en general que, al negar la respiración de Dios (D.L. IX 19), Jenófanes parece haber justamente replicado a una concepción de Pitágoras (ver nota anterior). Que el dios único de los fragmentos literales de Jenófanes (Xen. 21 B 23-26) fuera igual al Todo lo sugiere, por ejemplo, Platón (Sophist., p. $242 \mathrm{c}-\mathrm{d}$ ), aunque muchos estudiosos modernos piensan que puede tratarse solamente de una categoría doxográfica (la de los 'unitarios') fabricada exprofeso por el filósofo ateniense para sus fines expositivos. En realidad la identidad Uno = Todo está atestiguada expresamente sólo para Meliso (30 B 6 D.-K.), que argumentaba que $\tau$ ò ôv era infinito.
} 
P. Yo no sé qué pueda ser el Uno, no entra en la serie de los números. Las cosas comienzan con el Dos, como comienzan los números. Cuando tú y yo nos encontramos nace el diálogo de la vida. Del Dos a la Década, los números sirven para contar, pero también irradian fuerzas sobrenaturales y creadoras. El Tres es matrimonio, el Cuatro es justicia, el Siete es el tiempo bien medido (las tres medidas de cada objeto, y el tiempo en que se juntan y que por ellas resulta mensurable), el Diez junta en sí la perfección. Después de la Década, los números cuentan, pero no engendran: son hijos cuya fortuna guardan los diez números paternos. ${ }^{37}$

J. Me río de tus números. Me río de tus palingenesias. Ojalá te vea convertido en perro, para zurrarte a palos. ${ }^{38}$

P. Suenas como cuerda destemplada. ${ }^{39}$

J. Te hallo candoroso y milagrero, como el que veía las anguilas vivas dentro del agua hirviente, $\mathrm{y}$ a quien tuve que recomendarle que, otra vez, hirviera sus anguilas en agua fría. ${ }^{40}$

P. Te invito a callar ...

J. ¿Porque no quiero seguirte el juego? Laso de Hermíone quería obligarme a echar los dados. Me negué y me llamó cobarde. "En efecto, le contesté: me asustan las insensateces." 41

\footnotetext{
${ }^{37}$ Reyes se inspiró para este párrafo en la doctrina pitagórica del Uno o Mónada, que las fuentes describen no como inicio de la numeración sino como principio generador de los objetos sensibles, un status ambiguo que llevó a Aristóteles a preguntarse cómo se habría constituido el primer "uno" dotado de magnitud (Arist., Met., M 6. 1080 b 16). Por su lado, las especulaciones aritmológicas del pitagorismo, que conectaban ciertos números con determinados conceptos o cualidades, eran ya bien conocidas en el siglo IV a.C. (Arist., Met., M 4. 1078 b 21; [Arist.] M. Mor., A 1.1182 a 11), destacando en particular la simbología del 10, que se encuentra ya en un fragmento de Filolao en el siglo v a.C. (Philol. 44 B 11 D.-K.; cf. Luc., de lapsu in sal., 5, y Aët., I 3, 8).

${ }^{38}$ En este punto Reyes está reelaborando la sátira de la transmigración de las almas contenida en Xen. 21 B 7 D.-K., donde Pitágoras es caricaturizado en el acto de reconocer el alma de un amigo reencarnado en un perro.

${ }^{39}$ El reproche lanzado aquí a Jenófanes consiste en tachar sus palabras de contrarias a la armonía, concepto básico de los pitagóricos al que se atribuía un rango divino, como vimos arriba a propósito del texto de Luciano (nota 16).

${ }^{40} \mathrm{La}$ anécdota sobre las anguilas es transmitida por Plutarco, de commun. notit., 46, 3, p. $1084 \mathrm{~F}$.

${ }^{41}$ Anécdota también consignada por Plutarco, de vit. pud., 5, p. 530 E, donde, sin embargo, no se habla de cobardía ante las "insensateces" sino ante $\tau \grave{\alpha} \alpha i \sigma \chi \rho \alpha ́$ ("los hechos vergonzosos").
} 
P. Eres colérico. ¿Será que comes animales? ${ }^{42}$

J. Una vez lavados el suelo y las copas y las manos, y que aquél me ciñe de guirnaldas y el otro nos acerca la salvilla de fragantes ungüentos, lo único que falta es beber y comer de lo que traigan. ¡Ah! Y echar primero el agua y después el vino. ${ }^{43}$ Aunque, cierto, no soy tan glotón como Simónides, que cambiaría su gloria de poeta por una buena pierna de res. ${ }^{44}$

P. ¿Y eres tú quien dice que el mundo es equidistante para todos lados? Luego confiesas que es redondo y finito. ${ }^{45}$ Aunque otras veces te complaces en imaginarlo infinito para hacerlo dios. ${ }^{46}$ Por una parte, consideras la tierra como infinita hacia abajo. Por otra, el aire, como infinito hacia arriba. ${ }^{47}$ ¿Cómo caben en tu esfera dos infinitos?

J. No confundas mi filosofía con mi sátira. A veces sólo me importaba acabar con la escandalosa historia de Urano y Gea, poniendo un infinito hacia arriba; y con la conseja del Tártaro infraterrestre, poniendo un infinito hacia abajo. Sólo he pretendi-

${ }^{42}$ Se trata del conocido tema de la abstención de comer carne de animales (defendido también por Empédocles 31 B 141 D.-K.) al que nos referimos antes, a propósito del texto de Luciano (nota 18).

${ }^{43}$ Paráfrasis, respectivamente, de Xen. 21 B 1 y 5 D.-K.

${ }^{44}$ Aquí hay una elaboración de Xen. 21 B 6 D.-K., cuya alusión a un personaje que recibe una "pingüe pierna de toro" llevó a Diels a pensar (pese a la negativa de otros estudiosos como Wilamowitz y Timpanaro Cardini) que se trataba de una invectiva contra un poeta de banquete como Simónides, cuya avidez Jenófanes atacó en otro contexto (Xen. 21 B 21 D.-K.).

${ }^{45}$ Aquí hay un eco de declaraciones polémicas acerca de inconsistencias detectadas ya en la Antigüedad en las doctrinas de Jenófanes, justamente a propósito de la forma, la extensión y el surgimiento del universo (Theodoret., IV 5, derivado de Aecio según Xen. 21 A 36 D.-K. - cf. también nota siguiente).

${ }^{46}$ En esta parte del texto, Reyes parece haberse inspirado en las informaciones doxográficas proporcionadas por el tratado pseudo-aristotélico de Melisso Xenophane Gorgia, c. 4, donde, sin embargo, parece haber confusión con doctrinas de Parménides, a quien se debe la concepción del Ser como redondo y en perfecto equilibrio desde el centro (Parm. 28 B 8, vv. 42 ss. D.-K.), y de Meliso, cuya doctrina de la infinitud del ser ya mencionamos (véase nota 36 ).

${ }^{47} \mathrm{La}$ fuente de las dos frases anteriores parece ser Xen. 21 B 28 D.-K., con cierta manipulación por parte de Reyes, pues ahí Jenófanes no plantea una extensión infinita del aire hacia arriba, sino afirma más bien que el borde superior de la Tierra "se ve a los pies" del observador, "acercándose al aire". 
do explicar que ni arriba ni abajo del mundo acontecen episodios poéticos como los que cuentan Homero y Hesíodo, sino grandes evoluciones de fuerzas sobrehumanas. ${ }^{48}$

P. Ahora sí que nos entendemos.

En torno a los filósofos revolotea una mariposa, sólo conspicua entre los griegos por su ausencia de la poesía. Pitágoras la atrapa y, asiéndola delicadamente, la contempla en silencio.

J. ¿La Diosa-Madre de los cretenses?

P. No: un número.

Ésta es, pues, la manera en que Alfonso Reyes recreó el imaginado encuentro entre los dos pensadores jonios exiliados en Italia, aprovechando de manera altamente creativa los testimonios antiguos, de los que, sin embargo, da una interpretación en general bastante atinada. Es de observarse cómo el escritor mexicano, pese a la situación en que se encuentra de dar vida a un diálogo razonablemente verosímil entre Pitágoras y Jenófanes, hace un uso - que podemos calificar con justicia de 'filológico' - de informaciones doxográficas y de fragmentos textuales, cuyo sentido e implicaciones totales no siempre conocemos a ciencia cierta, pero que él logra combinar con bastante habilidad y casi sin violentar el sentido más probable de las fuentes originales.

Dado este procedimiento de investigación documental y de integración de los datos en un contexto conversacional, los puntos de contacto de Reyes con el texto de Luciano son abundantes, sobre todo en lo que respecta a los elementos básicos de la doctrina pitagórica. Las doctrinas esotéricas de la transmigración e inmortalidad de las almas, el vegetarianismo con ésta conectado y la imagen que Pitágoras cultivó de sí mismo

${ }^{48}$ Ya habíamos encontrado al inicio del texto de Reyes la severa crítica dirigida por Jenófanes contra la mitología tradicional representada por Homero y Hesíodo (ver las referencias indicadas en la nota 30). El concepto de "fuerzas sobrehumanas" introducido por Reyes, sin embargo, resulta más bien extraño al pensamiento de Jenófanes, que está empeñado en encontrar explicaciones lógicas y naturales para los fenómenos (véanse, por ejemplo, los fragmentos Xen. 21 B 30-32 D.-K.). 
como un ser cuasi-divino, son rasgos que se encuentran con diferentes matices en ambos autores. Ahora bien, en cuanto a los aspectos más científicos de la enseñanza pitagórica, donde Luciano se conforma con la mención chusca de la especulación aritmética acerca de la década, que ve contenida en potencia en el número 4 y encerrada en el simbolismo de la

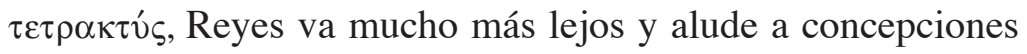
mucho más profundas y complejas, que implican una compenetración más 'profesional' con el contenido matemático del pitagorismo. En este rubro se cuenta, por ejemplo, la sutil alusión que introduce al descubrimiento de la inconmensurabilidad y de los irracionales por parte de Pitágoras (o de alguno de sus seguidores inmediatos), en la que deja percibir la honda conmoción que esto habría causado en su percepción de las magnitudes geométricas.

Por otro lado, es natural que el mismo planteamiento del diálogo así como los participantes en él influyan decisivamente en el cariz que toma la conversación en cada caso, pues mientras que Luciano, interesado como está sobre todo en la sátira, propone como interlocutor de Pitágoras a un personaje anónimo y presumiblemente poco informado, representante en todo caso de la mentalidad común, Alfonso Reyes introduce como antagonista dialógico del filósofo de Samos a Jenófanes, un conocido y formidable adversario ideológico de aquél, lo que da a su intercambio dialéctico un giro conceptual más amplio. De este modo, la pieza de Reyes se convierte en un ejemplo sobresaliente de texto divulgativo particularmente efectivo, aunque atípico para nuestras normas actuales, pues rompe con los esquematismos de la exposición descriptiva erudita para echar mano de un antiguo recurso desarrollado en la misma Antigüedad griega, el diálogo filosófico. Éste es, en efecto, un poderoso instrumento de proyección dramática de discusiones y conceptos filosóficos que se presentan así en su dimensión viva y dinámica, in fieri, como reproduciendo el proceso del que surgieron, cuya naturaleza no acabada reflejan. Dicho ins- 
trumento, cuyo punto de partida embrionario se puede discernir en los agones verbales del género teatral y en los discursos intercalados en las obras narrativas del siglo v a.C., habría de alcanzar en manos de Platón, el insuperable artista de las palabras y las ideas, un nivel de sofisticación insuperable, quedando como objeto de admiración y modelo de imitación para las generaciones posteriores.

Un nuevo impulso y una renovación de los procedimientos de representación dramática del diálogo filosófico habrían de llegar con la sátira menipea y con la decisiva intervención de Luciano de Samosata, con lo que el género tomaría una orientación más francamente scóptica, sin sacrificar del todo su componente cognitiva original. Tras el prolongado hiato de abandono en que quedó desde el final de la Antigüedad - si bien interrumpido brevemente por los grandes humanistas de los siglos XV y XVI, sobre todo Erasmo y Vives - el diálogo de ideas conoció ya sólo episódicos lapsos de momentánea restauración, entre los que se puede contar la creativa intervención de Alfonso Reyes que aquí analizamos. El diálogo contenido en su ensayo "Los filósofos de las islas" es, pues, un espécimen de un poco frecuente esfuerzo por traer a la vida no sólo un género literario poco cultivado en la época moderna, sino sobre todo por proyectar de manera dramática, como ilustró ejemplarmente Platón, el pensamiento y las doctrinas de unos personajes que contribuyeron a sentar las bases tanto de la filosofía como de la ciencia modernas.

Así pues, desempolvar el intento divulgativo en clave platónica que Reyes hizo de la filosofía griega antigua en el texto aquí analizado, poniendo énfasis en su procedimiento de reconstrucción filológica al estilo de Luciano, que vino aparejado a su rescate de la forma literaria del diálogo, podría tener interés no sólo para los filólogos clásicos interesados en los mecanismos de recepción del legado antiguo, sino sobre todo para los estudiosos de la cultura mexicana contemporánea y de su proceso aún no acabado de amalgamación de influencias varias. 